\title{
Inovação Organizacional e Tecnológica na Fruticultura Orgânica*
}

\author{
José Norberto Muniz
}

Departamento de Economia Rural - UFV

Paulo César Stringheta

Departamento de Tecnologia de Alimentos - UFV

\section{RESUMO}

A inovação organizacional e tecnológica é uma proposta conceitual que procura superar as vulnerabilidades dos modelos de pesquisa que não explicitam formas de interação com os segmentos sociais. As vulnerabilidades dos modelos tradicionais de pesquisa são analisadas. O modelo alternativo é elaborado, a sua implementação, os resultados e os obstáculos são apresentados, tendo-se como referência duas situações empíricas, ambas voltadas à sustentabilidade social e ambiental. Contrapõe-se a orientação pesquisa-tecnologia à pesquisa-intervenção social atrelada aos pressupostos científicos, em que há necessidade de redefinição dos papéis e das funções das instituições. Interdisciplinaridade, interinstitucionalidade, monitoria e valores agregados à produção complementam os fundamentos do modelo proposto.

\footnotetext{
* Os autores agradecem os pareceristas anônimos pelas contribuições. Este artigo apresenta a sistematização teórica da pesquisa financiada pela FINEP, convênio 22.01.0442.00, desenvolvida no período de junho de 2002 a dezembro de 2004, coordenada pelo Prof. Paulo César Stringheta, sendo convenente a Fundação Arthur Bernardes, vinculada à Universidade Federal de Viçosa.
} 
Palavras-Chave | Construção de Modelo; Inovação Organizacional; Pequenos Produtores; Fruticultura Orgânica; Interdisciplinaridade

Códigos JEL | O31; O32; O13; Q1; Q16

\section{ABSTRACT}

The organizacional and technological innovation model is a conceptual proposal that tries to overcome the research model vulnerabilities that does not show interaction forms with the social segments. These traditional model vulnerabilities are analyzed and the social segments are identified under two different empirical situations, considering the new patterns of values and behaviors related to the social and environmental sustentability. The orientation researchtechnology is opposed to the social research-intervention harnessed to the scientific principles. The new technological context is the way the instituitions and organizations act together at the local, regional and national levels. The additional issue is their role and functional redifinitions. Interactions effort among areas of knowledge are undertook, as well as interinterinstitutional actions, monitoring activities, and value added to the farm production complement the foundations of the proposed model.

KEYwORDS | Model Building; Organizational Innovation; Small Farmers; Organic Fruit Production; Knowledge System Interaction

JEL CODES I O31; O32; O13; Q1; Q16 


\section{Introdução}

O artigo apresenta o modelo de inovação organizacional e tecnológica como alternativa às diferentes formas de inserção da ciência e da tecnologia no sistema produtivo. Assumindo que o termo inovação é influenciado pelos conteúdos das proposições desenvolvimentistas ao longo da história, o exercício desta construção se restringe a um recorte de duas abordagens sobre a inovação tecnológica, o que permite identificar uma lacuna interpretativa, o que induz à delimitação de uma terceira abordagem. É a partir dessa terceira abordagem que se constrói a alternativa de inovação organizacional e tecnológica fundamentada empiricamente nos pressupostos da inserção de segmentos sociais em nichos de mercado orgânico.

O trabalho teórico e empírico constata que a presente proposta complementa as demais abordagens, e que elas possuem objetos empíricos distintos, como o produtor rural, a indústria urbana e os segmentos sociais. A fundamentação teórica do artigo está presente nos itens segundo e terceiro. ${ }^{1}$ A segunda seção identifica as vertentes behaviorista e econômica da tecnologia como inovação, diferenciando-as pelo alcance de suas interpretações, especialmente no que concerne à tematização da inovação em termos de sistema nacional.

É entre o comportamento inovador do produtor rural e o Sistema Nacional de Inovação que se introduz a pesquisa agropecuária. Se na primeira abordagem ela não é tematizada, na segunda ela não se insere no sistema de inovação, mas sempre se mostrou dinâmica na alteração do processo de pesquisa e de sua organização sob os propósitos de inserir a ciência e a tecnologia no sistema produtivo em nível de propriedade rural. Esta dinâmica é apresentada na terceira seção e se constitui na referência para inferir a noção de subsistema de inovação, especialmente em função das novas exigências que os fundamentos do desenvolvimento colocam às ciências agrárias, conforme apresentadas na quarta seção. A apresentação do modelo ocorre na quinta seção, sendo

\footnotetext{
Nesta fundamentação procura-se esclarecer significados específicos das abordagens, onde, p. ex., o significado de inovação organizacional e tecnológica não é o mesmo que o da organização da inovação, especialmente quando esta se refere a introduzir P\&D na própria empresa. Além disso, a proposta se fundamenta em princípios relacionados às atividades de pesquisa e aos condicionantes dos segmentos sociais excluídos do mercado tradicional de produtos, além de redefinir papéis dos atores institucionais. Sob o propósito da inclusão social admite-se que as alternativas como arranjos inovativos, clusters e Sistema Nacional de Inovação são conceitos que expressam proposições diferenciadas, mas complementares. $\bigcirc$ importante é que, por meio da inovação organizacional e tecnológica, as trajetórias de desenvolvimento podem ser fortalecidas.
} 
a implementação e os resultados apresentados nas seçōes sexta e sétima. Em ambas são identificadas as vulnerabilidades e a extensão do modelo para outras situações empíricas. Pelos resultados encontrados, a conclusão, na oitava seção, ressalta a viabilidade da proposta, mas condicionada à redefinição de papéis institucionais.

\section{Ciência, tecnologia e inovação}

A relevância desses termos ocorre pela importância que eles têm adquirido como componentes do desenvolvimento econômico. Historicamente, entretanto, a ênfase tem recaído sobre atores distintos do desenvolvimento. Por um lado, Rogers (2003), reforça os princípios behavioristas da inovação tecnológica, centrado no produtor rural, e, por outro, Rosenberg (1984) destaca a tecnologia sendo orientada para os diversos componentes do sistema econômico, concentrando-se, nas últimas décadas, no desenvolvimento industrial e nas aptidóes tecnológicas relacionados a produtos e processos. A diferença mais importante entre essas abordagens é que a segunda perspectiva inicia a problematização sobre a tecnologia, deixando de assumi-la como inovação em si, para abordar a questão do sistema que gera a tecnologia, direcionando a ciência como objeto de estudo da teoria econômica.

Empregando o conceito de Sistema Nacional de Inovação, Freeman (2004) não apenas identifica o campo de análise para a economia, como apresenta a sua origem histórica e as divergências empíricas entre regiôes continentais que permitiram o desenvolvimento, a introdução e a adaptação de novos produtos e processos nas economias nacionais analisadas. Nesse sentido, Albuquerque (2004) faz a apresentação dos principais representantes dessa abordagem teórica, realçando o conteúdo do conceito de sistema de inovação, a possibilidade da ação interdisciplinar entre a economia e as ciências sociais sob esse campo e, conseqüentemente, a sua importância para os tomadores de decisão em superar o atraso tecnológico. Para fundamentar empiricamente as proposições, estudos de caso são usualmente apresentados sobre as economias de industrialização recente, como, por exemplo, Coréia do Sul, Taiwan, Cingapura, Hong Kong, evidenciando estratégias e tendências das empresas voltadas à fabricação de produtos tecnologicamente complexos. 
Enquanto essas evidências apresentam como economias pobres e tecnologicamente atrasadas foram modernizadas, o behaviorismo também tem mostrado como produtores rurais se modernizaram, impulsionando a produção e a produtividade de culturas e animais, reorganizando o agronegócio brasileiro. Sobre essa última constatação, dados são suficientemente coletados pelos autores para evidenciá-la. Entretanto, há controvérsias quanto ao seu fator determinante e os seus impactos, especialmente porque a terra, como fator de produção, adquiriu importância social e política.

Sem aprofundar sobre essas controvérsias - a literatura é volumosa - a pesquisa agrícola tem sido objeto de análise crítica nos anos de 1970 e 1980, por ser estruturada e organizada pelos centros internacionais de pesquisa, como impulsionadora da Revolução Verde e, a partir dos anos 1980, pela pesquisa biotecnológica nos laboratórios das empresas transnacionais. Em ambos os momentos, a pesquisa para o setor agrícola não tem sido apreendida como componente do Sistema Nacional de Inovação. Evidentemente, há inúmeros fatores associados a isso, mas um deles é a própria característica do processo dessa pesquisa que, apesar de seguir os cânones científicos, possui peculiaridades. Por exemplo, Busch e Lacy (1983), ao investigarem a escolha do problema de pesquisa pelos cientistas agrícolas estadunidenses, examinam o sistema social que permite a criação de "pesquisas agrícolas válidas", e é sob esse condicionante que o sistema nacional da pesquisa agrícola possui singularidades que não são compreendidas.

Mais especificamente, apesar do aumento da produção de alimentos, a fome atinge uma grande parte da população mundial. Além disso, os modelos de pesquisa agrícola difundidos para os países em desenvolvimentos são estruturados e organizados a partir da experiência de cientistas e administradores estadunidenses. São iniciativas inseridas nas políticas de cooperação fundamentada pela institucional building para a pesquisa, no qual os objetivos da pesquisa, os beneficiários da pesquisa e o contexto social onde a pesquisa se desenvolve são considerados como inquestionáveis (Busch \& Lacy, 1983).

Para aprofundar a compreensão dessas proposições, os autores apontam algumas de suas conclusões: a) a produtividade é o objetivo inquestionável da pesquisa agrícola, visando a solução de problemas tais como fome, pobreza; b) as áreas de conhecimento tendem a se especializar cada vez mais, mas não se 
integrando em um conjunto coerente que permita o desenvolvimento da interdisciplinaridade; c) a escolha do problema de pesquisa resulta de negociações, mas sob a determinação da avaliação pessoal do cientista; d) meios formais de comunicação científica tendem a orientar a identificação de problemas de pesquisas relacionados às disciplinas em si cada vez mais distante das demandas sociais; e) o cientista é visto como o principal beneficiário da pesquisa, publicando e obtendo reconhecimento por parte da comunidade acadêmica.

Por estas características, Busch e Lacy (1983) admitem que a pesquisa agrícola se consolida pelo modelo baconiano de ciência-tecnologia representado pela Casa de Salomão. Sob essa estrutura e organização, conflitos, desigualdades, desordens, seriam solucionados pelas alternativas tecnológicas apresentadas pelos componentes da Casa, dando-lhe uma função altamente utilitária, não de inovação, mas voltada ao bem-estar da população em geral.

A reorientação do modelo da pesquisa agrícola, procurando superar as suas críticas, surge pela assimilação de alguns pressupostos assumidos pela economia da tecnologia e da inovação. Um deles diz respeito à Pesquisa e Desenvolvimento (P\&D), não como um componente do Sistema Nacional de Inovação, mas como um componente isolado que deveria orientar processos de pesquisas vinculados aos processos produtivos e ser alvo, conseqüentemente, de políticas específicas. Nesse sentido, a Empresa Brasileira de Pesquisa Agropecuária (EMBRAPA), como exemplo de gestão em C\&T, o que não tem ocorrido com as universidades agrícolas públicas, assume a investigação agropecuária em termos de $\mathrm{P} \& \mathrm{D}$, priorizando as demandas dos clientes, usuários e beneficiários da pesquisa, gerando conhecimentos atrelados às necessidades econômicas e sociais (EMBRAPA, 1993).

Se a utilidade da ciência passa a ser a inovação tecnológica, como produto do sistema de conhecimento, a ênfase em P\&D, como um tipo de pesquisa, pouco ou nada tem acrescentado ao sistema produtivo, pois há um hiato entre a pesquisa e esse sistema em países em desenvolvimento. Portanto, a questão principal, em se tratando de inovação tecnológica, é compreender esse hiato e não simplesmente definir opções ou identificar, aleatoriamente, estratégias que possuam a pretensão de reduzi-lo. Entre esses dois esforços, enquanto o primeiro é raramente exercitado, o segundo é mais comumente realizado, sem, contudo, obtenção de resultados efetivos nesse procedimento, pois, conforme 
admitiu Goldstein (1995), a ciência e as tecnologias geradas, nos países subdesenvolvidos, não têm solucionado problemas sociais e políticos.

Além disso, conceitualmente, $\mathrm{P} \& \mathrm{D}$ são dicotomias abstratas que induzem à concepção de ciência fundamentada na tecnologia, mas - essa é a diferença importante - como estratégia específica que induz ao desenvolvimento industrial urbano (Callon, 1995). A ênfase ao conteúdo rural de P\&D adveio da importação desses termos, que nem sempre são apreendidos de forma consensual. Os cientistas pesquisados por Busch e Lacy (1983), por exemplo, mostraram dificuldades em categorizar as suas pesquisas em pesquisa básica, pesquisa aplicada e pesquisa e desenvolvimento, conforme a definição da National Science Foundation. Dependendo da instituição financiadora, a mesma proposta recebia adaptaçōes no seu encaminhamento. Além disso, Mowery e Rosenberg (2005:192) chamam a atenção para “... o que é chamado de P\&D é algo diferente da ciência em si. Aproximadamente, dois terços dos investimentos estadunidenses em P\&D estão no D", ou sejam, são investimentos em planejamento, teste do produto, re-design, alternativas no processo de produção. Por sua vez, Howard (2005) estende a crítica aos investimentos em P\&D como condição suficiente para o desenvolvimento industrial. Para este autor, a transferência tecnológica estrangeira é que se constitui no fator mais importante para o desenvolvimento da Coréia do Sul e de Taiwan, e não apenas as instituições de P\&D.

De forma mais incisiva, Howard (2005) argumenta que a alavancagem industrial dos países em desenvolvimento não está na fronteira do conhecimento, mas depende da transferência dos conhecimentos existentes nos países industrializados. Como a maior parte desse P\&D, conforme constatam Mowery e Rosenberg (2005), não tem sido ciência, seja básica ou aplicada, e como o investimento em P\&D é apenas um indicador da capacidade tecnológica nacional, conforme admite Mark (2005), além de constatar que a base científica das economias de industrialização recente é frágil, esses autores sugerem outros determinantes, como a aquisição de licenças, a engenharia reversa, investimentos na aquisição de equipamentos e melhoria das aptidões, política macroeconômica, além da relevância geopolítica desses países.

Ciência, tecnologia e inovação, conforme as tendências interpretativas apresentadas, não têm sido objetos de proposições convergentes, pois, aparentemente, há propósitos distintos, como o produtor rural, a indústria urbana e 
os segmentos sociais. Enquanto a indústria urbana é inserida no Sistema Nacional de Inovação, a pesquisa agrícola, de forma mais restrita, é contextualizada no sistema social, não necessariamente inovador e nem ousado. Se há variáveis restritivas nesse contexto, isto também é identificado sobre o produtor rural, mas centrada mais no ator do que no seu contexto. Pela identificação do objeto da inovação, como o produtor rural, os segmentos sociais e a indústria urbana, e a sua abrangência conceitual, pode-se propor que as abordagens apresentadas sejam complementares. Entretanto, assumir complementaridade não é suficiente, ela requer interpretação, o que implicaria outro tipo de análise, procurando inserir, principalmente, o sistema de pesquisa agrícola no Sistema Nacional de Inovação, voltado para reorganizar produtos e processos produtivos das indústrias urbanas e dos produtores rurais. $^{2}$

Evidentemente, isto implicaria aprofundar na interpretação do conteúdo do conceito de Sistema Nacional de Inovação, trabalho este que não é objeto deste artigo. Pelo contrário, é em função das pressuposições das abordagens apresentadas, que se sugere uma proposta complementar a elas, mas diferenciada de todas. Esta diferença, como será demonstrada, está na distinção entre inovação organizacional e tecnológica - centrada na organização do ambiente institucional - e inovações tecnológica, de gerência e de organização da empresa. Em certo sentido, é rever o papel da mudança tecnológica no desenvolvimento, mas conceituando o desenvolvimento em termos da inclusão de segmentos sociais em novos nichos de mercado.

\section{Processo e organização da pesquisa}

Esta seção desenvolve uma das abordagens apresentadas na anterior. Enquanto aquela delimitou abordagens sobre a ciência, a tecnologia e a inovação, esta a complementa ilustrando como o processo e a organizaçáo da pesquisa agrícola têm se constituído em ciência, tecnologia e inovação. Por processo e organização, entende-se que a pesquisa apreendeu, inicialmente, o setor produtivo por culturas isoladas, visando o aumento constante da sua produtividade, pela apropriação e exploração intensiva dos recursos naturais, centrada em

2 Paez (2001) introduziu o termo "inovação do agronegócio", em trabalho teórico desenvolvido a partir dos conceitos de custo de transação e dinâmica da firma, derivados da nova economia institucional. 
produtos tradicionais na pauta dos mercados interno e externo. Essa apreensão ocorre sob a redução da base epistemológica das disciplinas, privilegiando o mundo natural, com o propósito de inserir o produtor no mercado de produtos, por meio da inovação tecnológica gerada.

Nota-se que essa noção de processo não se fundamenta apenas no método de investigação científica, mas nos princípios sob os quais o sistema produtivo agrário é apreendido. Além dessa delimitação, outra pode ser adicionada, que é a pressuposição sobre a homogeneidade dos produtores. Assim, o processo de pesquisa é "ofertante" de tecnologias, assumindo que todos os produtores rurais teriam acesso a elas, apenas com mudanças de valores e comportamentos. Mais especificamente, o "behaviorismo" do processo de difusão, como explícito em Rogers (2003), prevê a mudança de valores e de comportamentos tradicionais para modernos como pré-requisitos à adoção de tecnologias, que deveriam ser acompanhados de medidas facilitadoras, como créditos e orientações para a contabilidade em nível de propriedades. Na introdução de instrumentos e equipamentos, a racionalidade instrumental tornou-se mecanismo que propiciava a vinculação entre a geração da inovação e a sua introdução no sistema produtivo.

Teoricamente, havia a pressuposição de que o hiato não existia nessa fase de introdução das inovações tecnológicas. Entretanto, empiricamente, verificava-se, especialmente pelos estudos de adoção de tecnologias, que as inovações não chegavam a todos os produtores rurais, mesmo entre aqueles considerados inovadores. Assim, os mecanismos indutores de difusão e de adoção de tecnologias não eram suficientes para atingir os produtores rurais, revelando uma das falácias do processo de pesquisa, que foi assumir a homogeneidade do público-alvo da pesquisa.

A base tecnológica das investigações, estruturada disciplinarmente, permitiu a organização da pesquisa em instituições, tanto de ensino quanto de pesquisa. Entretanto, entre essas instituições, fortalecidas pelas políticas de fomento e aquelas "criadas" para difundir as tecnologias, predomina o isolamento, o que corrobora as pressuposiçóes que regiam o processo de pesquisa. A despeito dessa constatação, poucas alterações ocorreram nos países subdesenvolvidos, no processo e na organização da pesquisa e, quando ocorreram, eram induzidas por modelos importados dos centros internacionais de pesquisa. 
A primeira inovação no processo de pesquisa foi gerar inovações tecnológicas para grupos de produtores rurais, estratificados segundo critérios técnicos, econômicos, sociais e culturais. Assim, as inovações seriam adaptadas a essas condições, gerando pacotes tecnológicos para três grupos distintos: pequeno grupo de grandes produtores; grupo intermediário de produtores rurais; e grande grupo de produtores sem recursos. Sob essa tendência, a homogeneidade deixa de ser assumida para ser trabalhada, obtida tecnicamente pela combinação de diferentes tipos de variáveis analisadas por técnicas estatísticas multivariadas, como a análise fatorial.

Outra característica importante dessa ênfase seria a capacidade inerente à pesquisa técnico-científica em gerar tecnologias socialmente adaptadas ao critério de menor custo. Com isso, mantém-se a pressuposição de que o produtor se insere no mercado de um produto somente se ele adotar inovaçôes tecnológicas. Evidentemente, se há a estratificação de produtores, a pesquisa assume que aqueles que possuem mais recursos financeiros poderiam ser inseridos mais intensamente.

Como essas pressuposições não foram empiricamente sustentadas, a segunda alternativa no processo de pesquisa consistiu na introdução do farming system research, que é uma abordagem sobre como a pesquisa deveria focalizar a propriedade rural. Sob a constatação de que as inovações não eram adotadas, tanto por produtores isolados como pelos agregados estatisticamente, a preocupação dos pesquisadores deveria ser com a apreensão da exploração na propriedade sob a perspectiva sistêmica, requerendo a formação de equipes multidisciplinares, contrastando com o enfoque disciplinar anterior. ${ }^{3}$

Nota-se que, na alteração do processo e da organização da pesquisa, há a de perspectiva, apreendendo a propriedade como unidade produtiva e não uma cultura sendo explorada por pacotes tecnológicos. A relevância do processo de pesquisa se sobressaía pelo fato da investigação ser realizada na propriedade, afastando-se da estação experimental e dos laboratórios. Com isto, as pesquisas aplicadas e adaptadas às propriedades são reforçadas.

Como essa estratégia também não foi suficiente para eliminar o hiato entre as inovações tecnológicas geradas e a sua introdução no sistema de produção na

3 Com a constituição dessas equipes inicia-se a participação de cientistas sociais com o propósito de diagnosticar e apreender, junto aos produtores rurais e suas famílias, informações que pudessem subsidiar a pesquisa técnica. Por outro lado, no âmbito da pesquisa disciplinar, as ciências sociais aparecem como facilitadoras para a inserção das inovações tecnológicas na atividade agropecuária. Enquanto a economia calculava custos e combinava fatores de produção, a administração rural introduzia técnicas de registro de informações, a sociologia abordava os determinantes socioculturais da adoção tecnológica e a comunicação investigava meios eficientes de difusão das inovações para atingir os produtores rurais. 
propriedade, outra alteração foi introduzida, focalizando a atenção do pesquisador sobre a propriedade e, pela primeira vez, sobre o produtor rural. É a estratégia designada como farming participatory research, por meio da qual o produtor assumia a função de se envolver com a pesquisa, mas apenas no diagnóstico do problema prático que ocorria na propriedade.

Deve-se destacar que a essa estratégia de pesquisa outras foram acrescentadas, como o farming system research \& extension. No conjunto, elas são, freqüentemente, redefinidas pelas novas técnicas de participação empregadas para identificação do sistema de conhecimento local, envolvendo os produtores e as famílias, com múltiplos propósitos de apropriação e exploração dos recursos. Se, por um lado, foi possível identificar problemas e alternativas, propiciando o desenvolvimento de tecnologias adaptadas e de ações desenvolvimentistas localizadas, por outro, essa perspectiva de processo de pesquisa continua fortalecendo o indivíduo ou o grupo na participação para identificação de problemas práticos.

Como conseqüência, houve a redefinição do papel do extensionista rural, que se constituía no elo entre o produtor e o pesquisador, fornecendo informações e interpretações do mundo rural, pois, pela forma como as pesquisas eram ensinadas e executadas nos centros de investigação, os pesquisadores não deveriam possuir essa habilidade. De certa forma, essa alternativa no processo de pesquisar constatava a dissonância entre a interpretação técnica, que se apropriava dos recursos naturais produtivos e o significado que o produtor atribuía a sua propriedade, que freqüentemente não seguia a orientação técnico-instrumental. Por outro lado, esse modelo reafirmava a vinculação imediata entre o produto da pesquisa e o produtor rural, ignorando o mercado das inovações e, conseqüentemente, o papel das empresas no processo de pesquisa.

Tanto teórica como empiricamente, as questões práticas eram apresentadas nas propriedades, mas concebidas e investigadas sob os propósitos das indústrias que estruturam, sob incentivos das políticas nacionais e oportunidades de expansão econômica, um mercado consumidor dos seus produtos. ${ }^{4}$ As ocorrências advêm desde os experimentos de Liebig, passam pela redescoberta

\footnotetext{
4 É Sohn-Rethel (1983), na crítica radical à tecnologia, que emprega o conceito de falsa consciência necessária para expor que o conhecimento científico é delineado pelas leis do mercado, não envolvendo a completa racionalização do homem. Com os mesmos propósitos, Lukács (1989) emprega o termo segunda natureza para designar a redução do mundo social a um sistema mecânico, integrando atores sociais em sistema de relações "coisificadas", impessoais. A confluência desses dois conceitos e suas implicações na compreensão da organização da pesquisa agrícola encontra-se em Muniz (1995).
} 
das leis de Mendel e chegam à biotecnologia. ${ }^{5}$ Os estudos de Liebig versavam sobre a relação entre agricultura e química e foram, em razão da crise da fertilidade natural do solo, foram intensificados em 1837 para atender a demanda que a fertilidade do solo representava para o desenvolvimento da sociedade capitalista (Foster, 2000). Após esses estudos, Liebig publicou, em 1840, o livro Organic Chemistry in its Application to Agriculture and Physiology, em que apresenta as explicaçôes sobre a interferência do nitrogênio, do fósforo e do potássio no crescimento das plantas. Entretanto, foi o agrônomo inglês J. B. Lawes, que competia com Liebig, que inventou, em 1843, um meio de produzir fosfato solúvel, surgindo o primeiro fertilizante, conforme enfatiza Foster (2000). É interessante destacar, que entre a proposta de Liebig e a de Lawes, os propósitos são diferenciados. Enquanto o primeiro ressalta a importância da restituição de elementos, permitindo o retorno das condições de fertilidade do solo, o segundo avança na apresentação de inovaçôes para construção de uma estrutura que permite a oferta dos elementos requeridos. Apesar disso, ambos têm em comum a exploração racional da agricultura, com vistas na intensificação de produção das culturas.

Com relação à Revolução Verde, os mesmos princípios orientaram o desenvolvimento das inovações e, em especial, a de sementes mais produtivas, designadas de high-yielding varieties. Isto ocorreu, principalmente, devido à redescoberta das leis de Mendel, no início do século XIX, associada à possibilidade de produzir sementes que pudessem ser comercializadas, estabelecendo as condições técnico-científicas para a Revolução Verde. Portanto, a inovação principal não foi da semente isoladamente, mas consistiu na possibilidade de associar as sementes aos inputs necessários à sua reprodução, revelando a complementaridade entre um fator de produção e a combinação, determinada pela relação custo e produtividade dos demais componentes.

Apesar da ênfase atribuída à pesquisa básica desenvolvida nos laboratórios das universidades públicas estadunidenses, o que justificou a produção de highyielding varieties foi o interesse comercial que elas despertam (Berlan \& Lewontin, 1986). Para esses autores, a ciência é que permite a incorporação da tecnologia no sistema produtivo das indústrias, tornando evidente a combinação desse interesse com a descoberta sobre o vigor híbrido, o qual é recuperado a partir do momento em que duas linhagens puras são cruzadas. Para a indústria, isto

\footnotetext{
5 A dimensão econômica da biotecnologia é, inclusive para Goldstein (1995), o que diferencia a biotecnologia praticada no Primeiro Mundo daquela executada no Terceiro Mundo, pois, no seu programa de pesquisa, não é incluído a geração de lucros pela invenção de produtos de alto valor agregado no mercado internacional.
} 
era de fundamental importância, uma vez que direcionava os produtores rurais, a adquirir novas sementes no mercado todos os anos e não selecioná-las na própria propriedade. ${ }^{6}$ Portanto, os critérios que orientaram a pesquisa sobre o melhoramento das variedades seriam derivados do mercado, e não daqueles que os produtores vislumbravam para a sua produção.

Esse aspecto torna-se mais evidente na pesquisa biotecnológica. Isto ocorre, como admitiu Goldstein (1989), como conseqüência dos novos processos de pesquisa construído sob arranjos institucionais que permitem interaçôes entre áreas de conhecimento complementar, como a genética molecular, a biologia molecular, a química orgânica, a física, a matemática, a computação e a eletrônica. Como processo de pesquisa e como organização, a biotecnologia afastase totalmente das diretrizes estabelecidas na Revolução Verde. Além do enfoque sobre o melhoramento de determinadas commodities em solos produtivos, delimitados por zonas geográficas, apontadas por Buttel et al. (1985), é preciso compreender o conteúdo e a intensidade com que o setor privado se envolve na pesquisa biotecnológica.

A questão não é, meramente, a apropriação do produto gerado pela pesquisa, mas a dependência da pesquisa biotecnológica para com a indústria biotecnológica. É o estágio de desenvolvimento da ciência e da tecnologia em que há nítida separação e, ao mesmo tempo, dependência entre o produto biotecnológico e os equipamentos e instrumentos que caracterizam o novo processo, e a organização desta pesquisa, que passa a gerar e transmitir informações precisas e rápidas, além de grande capacidade de armazenamento.

Esse sistema de tecnologias complexas é, para Castells (2000), a quinta característica do novo paradigma tecnológico da sociedade do conhecimento. Para esse autor, as demais características são: 1) a informação é a matéria-prima a ser obtida; 2) há penetrabilidade dos efeitos das novas tecnologias em todas as dimensões socioeconômicas e culturais; 3) a morfologia de rede é a forma de organização dos componentes do paradigma; e 4) as redes possuem papéis específicos, como ganhar posições e melhorar a comunicação.

Portanto, o processo e a organização da pesquisa agrícola saem da disciplinaridade para constituir-se em domínio das tecnologias de informação, à qual se acrescentam as tecnologias da microeletrônica, da computação (software e

\footnotetext{
6 Para Berlan \& Lewontin (1986), o processo de pesquisa que desenvolve o milho híbrido transforma a semente em uma
} commodity, diferentemente dos argumentos de economistas, de que o milho, a soja, etc., se constituam em commodities. 
hardware), da telecomunicação/radiodifusão e da optoeletrônica. Para Castells (2000), a engenharia genética, ao concentrar-se na decodificação, manipulação e reprogramação dos códigos genéticos, passa a convergir nas suas aplicaçôes métodos e materiais, para a eletrônica e a informática.

Sob essa perspectiva, a incorporação da ciência e da tecnologia nos sistemas produtivos ocorre se as áreas de conhecimento podem se expandir em função da indústria do conhecimento. A ciência, a tecnologia e a inovação se interpenetram conceitual e empiricamente, gerando inovaçôes na gestão e na organização internas, tanto dos centros de pesquisa quanto das empresas. Isto contrasta com a concepção linear entre ciência e inovação apresentada na seção anterior.

Da simplicidade da relação entre ciência, tecnologia e produtor rural, ela passa para indústrias de materiais e equipamentos que utilizam redes de conhecimentos para gerar a infra-estrutura de pesquisa. O que se considera "de ponta" é essa rede constituída de processos e de organização, e não simplesmente as informações que podem ser obtidas pela estrutura decorrente dessa rede. Ser usuário da rede é uma coisa, produzir componentes é outra. São estágios distintos de inovação da economia.

Economias em desenvolvimento, provavelmente não possuem o Sistema Nacional de Inovação que permita produzir componentes. Pelo contrário, passam, quando muito, a usufruir a nova forma de como o conhecimento e a informação se apresentam para o desenvolvimento da economia. Por sua vez, as economias de industrialização recente, por possuírem bolsões de competências, podem ser ilustrativas de sucesso de um processo e de uma forma organizacional de pesquisa. O que se advoga é que essa estrutura de processos e de organização requer complementaridades, induzindo alternativas de convivência científica e técnica e de exploração de novos produtos sob novos conceitos, o que começa a ser evidenciado a partir da seção seguinte.

\section{Determinantes de um novo modelo}

Os determinantes do modelo de inovação organizacional e tecnológica afastam-se dos determinantes que orientaram a reorganização dos processos e da organização da pesquisa apresentados até então. Os critérios estão explícitos pelos valores e normas que caracterizam a própria sociedade informacional, que passam 
a revelar conteúdos culturais e padrões sociais que se convertem em mecanismos regulatórios para a concepção e as ações. Na sociedade de informação, esses valores e padrões sociais podem ser exemplificados pela nova postura diante da alimentação, das dietas e da saúde de forma geral.

Mais especificamente, os exemplos desse mecanismo regulatórios são o safety food e o fair trade. Enquanto o primeiro enfatiza a qualidade do produto, o segundo se refere à dimensão social de sua produção. São dois termos com conteúdos complementares que, incorporados à sociedade de informação, passam a demonstrar que o comércio, valorizado pela dimensão sociocultural e não apenas econômica, pode constituir em instrumento de desenvolvimento sustentável. É um padrão estabelecido com propósitos de reverter desigualdades sociais e a degradação ambiental, não definido aleatoriamente, pois está organizado e estruturado por meio da certificação e de uma rede de instituições voltada a esse propósito. ${ }^{7}$

O importante é que essa estrutura e organização não competem com o free trade, que possui o propósito de reduzir as barreiras e investimentos das empresas, assegurando o direito de propriedade intelectual. ${ }^{8}$ À essa estrutura incorporam-se novos padróes que estabelecem novas qualidades dos produtos e de proteção às condiçõos de apropriação e exploração dos recursos humanos e naturais. Por conseguinte, são novas proposições que podem, ou não, reorientar o processo e a organização da pesquisa, dependendo, evidentemente, da apreensão desses dois conceitos, conforme explicitados anteriormente.

Se se mantêm a concepção clássica do processo e de organização de pesquisa, mesmo com a introdução dos novos parâmetros que podem reorientar a pesquisa, como a sustentabilidade, a segurança alimentar, a diversidade genética, a redução da pobreza e o direito de propriedade, a reorientação esperada não deve ocorrer. Continuar pesquisando sob os mesmos processos e organização torna o sistema de C\&T avesso às inovações.

Em outros termos, os determinantes da sociedade de informação são orientações necessárias à reorganização da pesquisa, mas não são suficientes. Pode-se pesquisar em função dos novos parâmetros, mas sob os princípios clássicos de processo e de organização. Por isso, a constatação da lentidão da inovação no

\footnotetext{
7 Para o conhecimento da origem, dos fundamentos e da estrutura da certificação em diferentes países e no Brasil consultar Vailati et al. (2003).

8 Como é o caso do North American Free Trade Agreement (NAFTA) e do General Agreement on Tariffs and Trade (GATT).
} 
processo e na organização da pesquisa. O exemplo típico é a pesquisa orientada para produtos e para o cliente, conforme apregoado pelo Bremerhavener Institut fur Lebensmitteltechnologie und Vioverfahrenstechnik (BILB). Neste Instituto, a investigação ocorre sob os mesmos processos e organização da pesquisa orientada para produtos na Revolução Verde, acrescentando a existência de um departamento sobre a avaliação sensorial de alimentos, visando à prestação de serviços voltada aos alimentos funcionais, aos alimentos seguros, à análise dos alimentos, aos materiais biodegradáveis, etc., conduzidos em uma unidade técnica altamente aparelhada. O importante é que, ao pesquisar sob os novos padrôes, os equipamentos, os instrumentos e os materiais passam, também, a ser referência para a pesquisa, a despeito dos componentes social e ambiental inseridos nesse novo padrão. Como conseqüência, a inovação passa a ser centrada nas tecnologias da pesquisa e nos possíveis produtos gerados, e não na sua organização.

Se o diferencial do novo padrão são os componentes social e ambiental, institucionalmente apresentados pela certificação, a proposição é de que esses componentes devem orientar o processo e a organização da pesquisa. A hipótese é que safety food e fair trade não geram apenas novos produtos, mas induzam aos novos processos e organização da pesquisa, pois são esses elementos, e não apenas os novos produtos, que irão reduzir o hiato entre a tecnologia e o sistema produtivo. Como conseqüência, se a certificação é sobre produtos orgânicos, e no presente caso a referência é a fruticultura, a produção passa a requerer formas alternativas de organizar a relação entre produtores e os demais atores desse processo, em decorrência da certificação requerida. Ser produtor orgânico não é preparar um produtor à imagem do "super-homem", mas preparálo para compreender e trabalhar a propriedade como um sistema sustentável, associado a outros produtores, interagindo com múltiplas instituições, que devem ser estruturadas e fortalecidas para atuarem sob esse novo contexto organizacional. Portanto, a inovação organizacional está atrelada a novos conceitos de um tipo de agricultura, à forma de inserir produtores organizados sob esses conceitos e à redefinição do papel institucional e do conhecimento científico em contexto de intervenção para o desenvolvimento local. ${ }^{9}$ Esses conteúdos, que representam a base conceitual do modelo de inovação organizacional, serão apresentados na seção seguinte.

9 Contrastando com os termos empregados anteriormente, a proposta de inovação organizacional se fundamenta no emprego do conhecimento científico para a intervenção e, diferentemente de outros modelos, não da pesquisa por produtos, etc. 


\section{A inovação organizacional e tecnológica}

A proposição inicial desse modelo é de que ele se constitua em alternativa complementar à capacidade transformadora das tecnologias. Por conseguinte, ele visa a constituição dessa capacidade e a exploração da potencialidade transformadora da tecnologia e das instituições por meio de intervenções sociais. $\mathrm{O}$ diferencial está na expansão do conceito e da aplicação do conhecimento científico-tecnológico no modelo, pois é um modelo que envolve projetos de pesquisa científica elaborados sob duas vertentes, a científica-tecnológica e a de intervenção socioinstitucional, ambas interagindo em etapas específicas ou complementares na implementação do modelo.

A fruticultura orgânica, como referência empírica, fornece a abrangência e a natureza da inovação organizacional e tecnológica a ser introduzida, pois ela requer a redefinição do espaço agrícola, dados os requerimentos existentes para a certificação dos produtos na delimitação da área de produção e as tecnologias a serem introduzidas na exploração desse espaço. Por princípio, a produção orgânica depende desse espaço e de três outros, que são a residência dos produtores na propriedade, o entorno do espaço a ser explorado na propriedade e o entorno do espaço além da propriedade.

São quatro dimensões que devem ser compatíveis entre si, em termos de organização e de exploração. Mais especificamente, orientações científicotécnicas e intervenções devem ser introduzidas nos quatro espaços, isoladamente e/ou simultaneamente, dependendo da complexidade organizacional e estrutural dos atores socioeconômicos, com o propósito de preparar o empreendimento para a certificação dos produtos. Assim, o rearranjo para a intervenção local passa a ser delimitado pela proposição da certificação e pela disponibilidade, pelo interesse, pela experiência e pelo conhecimento do público-alvo com a dimensão orgânica da exploração e com a certificação. Para melhor compreender essas proposições, o modelo é apresentado na Figura 1. Ele é construído sobre dois pilares: o inventário, que representa o conhecimento científico-tecnológico existente, e a organização da produção, que expressa os atores sociais e instituições. Ambos estão conectados por linhas contínuas, que significa que há relações de associações e implicações entre conhecimento técnico e conhecimento local, e linhas seccionadas, que revelam a necessidade 
FIGURA 1

Representação do Modelo de Inovação Organizacional e Tecnológica

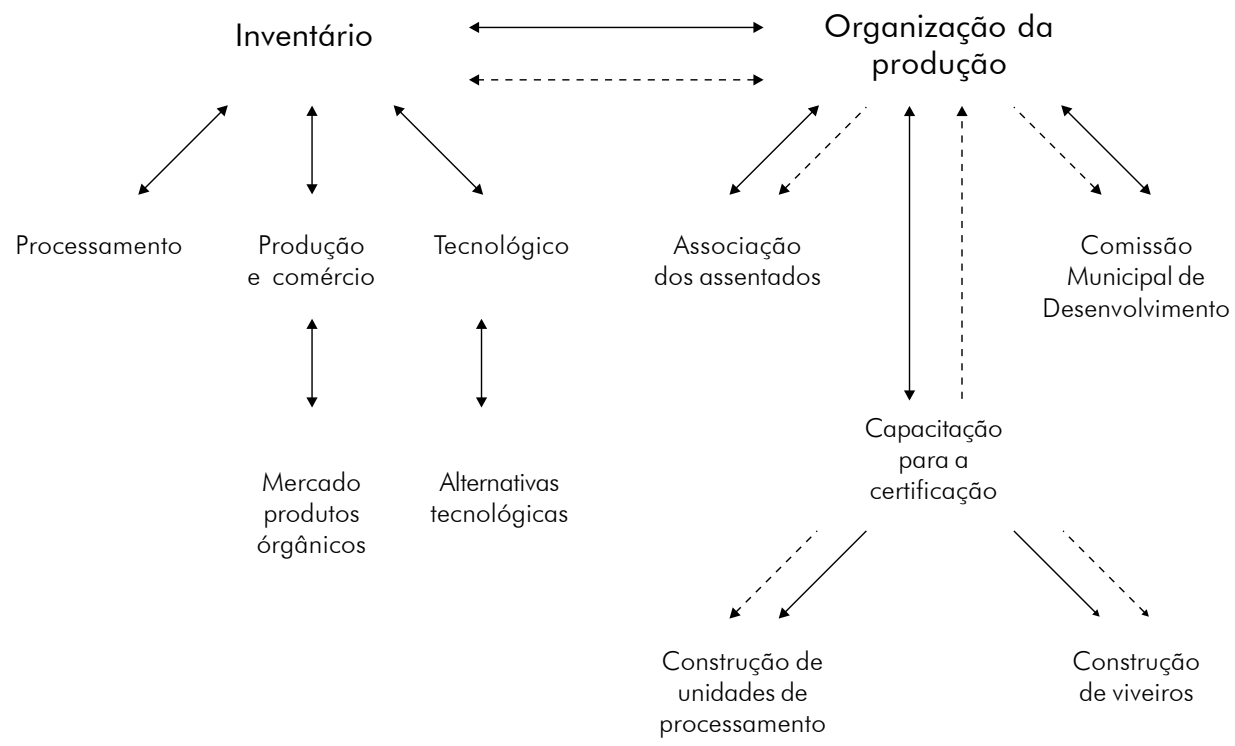

Fonte: elaboração própria.

de ações de capacitação de recursos humanos e de fortalecimento institucional na fruticultura orgânica.

O inventário possui a função de apresentar o "estado da arte" em relação às tecnologias existentes, tanto de produção como de processamento, e os produtos com os seus respectivos mercados. É a inserção da orientação técnicainstrumental para definir a natureza do empreendimento a ser introduzido. Esse inventário requer o envolvimento técnico-científico no levantamento dos condicionantes tecnológicos, econômicos e institucionais.

A organização da produção começa a se estruturar pelo envolvimento de organizações locais. Para o caso da pesquisa, foram a Associação dos Assentados e a Comissão Municipal de Desenvolvimento Rural Sustentável. As linhas contínuas e seccionadas expressam interaçóes complexas, uma vez que se assume que os componentes desse segmento estão desestruturados, pela sua exclusão, como atores econômicos, em participar do mercado de produtos convencionais e não-convencionais. Como corolário, as demais instituiçóes envolvidas com o 
empreendimento também não estão fortalecidas para se envolverem com a inclusão de segmentos sociais.

Sob essa desestruturação, a referência inicial para a organização passa a ser a construção de viveiros e a unidade de processamento. Essas unidades, construídas em áreas de uso comum, passam a ser a referência para os produtores e para as instituições, pois requerem ações organizadas, orientações técnicas específicas e cooperação para estar capacitada para a certificação. Essas unidades possuem, portanto, três funções importantes no modelo: a) ser a referência técnica para a produção, transformação e comercialização do produto; b) ser a referência para os treinamentos; e c) ser o foco de extensão da organização integrada.

Como inovação organizacional e tecnológica, o modelo requer, principalmente, a monitoria e a avaliação contínua na sua implementação. Para tanto, há a necessidade de uma equipe voltada para esses objetivos, pois, mais do que se preocupar com a implementação das ações, o esforço redobrado deve estar voltado às correções das distorções e dos novos interesses que emergem com a própria inovação organizacional e tecnológica.

\section{Implementação do modelo}

O modelo foi implementado por uma equipe interdisciplinar ${ }^{11}$ em razão do conteúdo técnico da fruticultura orgânica, das características dos segmentos sociais e do envolvimento institucional necessário à intervenção. Essa equipe foi constituída de professores e estudantes dos seguintes departamentos: tecnologia de alimentos, economia rural, fitotecnia, solos e nutrição de plantas, administração, direito, zootecnia, educação, economia doméstica, agronegócio, engenharia agrícola e economia. ${ }^{12}$

As atividades iniciais de pesquisa visavam a construção de um quadro de referência sobre a fruticultura orgânica e sobre as instituições e locais onde o projeto poderia ser introduzido. Assim, pesquisas foram realizadas para identificar o "estado da arte" na produção, processamento e mercado da fruticultura

11 Conforme proposição de Muniz \& Ribeiro (2000).

12 Os membros da equipe foram informados sobre o conteúdo do projeto, bem como sobre a expectativa e a forma de atuação de cada um. Essa equipe exercia tanto atividades internas quanto externas, envolvendo instituições e, principalmente, construindo e monitorando interações entre as coletividades e as instituições. 
orgânica e para a identificação do público-alvo da pesquisa. Essa etapa permitiu, também, o envolvimento do Instituto Biodinâmico na capacitação dos técnicos do projeto, de professores e estudantes da Universidade Federal de Viçosa (UFV) e de técnicos de várias instituições sobre a certificação.

Na elaboração da proposta de pesquisa à Financiadora de Estudos e Projetos (FINEP) havia a identificação de que assentados, representados pela Associação, e pequenos produtores, representados pela Comissão Municipal, no Estado de Minas Gerais, seriam os segmentos sociais envolvidos pelo estudo. Entretanto, não havia a especificação empírica desses segmentos, o que deveria ser objeto de uma investigação sociopolítica e econômica.

Para a seleção das duas localidades, investigaçōes foram desenvolvidas junto às prefeituras, Empresa de Assistência Técnica e Extensão Rural (EMATER), Instituto Nacional de Colonização e Reforma Agrária (INCRA), Federação dos Trabalhadores na Agricultura do Estado de Minas Gerais (FETAEMG), sindicatos, utilizando-se dados secundários para identificar assentamentos e municípios que teriam potencialidade para participar do projeto. Nesta fase, dois critérios foram empregados: a) potencialidade para implantação da fruticultura orgânica, onde a área e a localização se sobressaiam como fundamentais; e b) localidades que já tinham tido experiência com o uso do Programa Nacional de Fortalecimento da Agricultura Familiar (PRONAF), especialmente pelo fato desse programa requerer algum nível de organização para acesso a ele.

Inicialmente, foram identificados 49 municípios localizados na Zona da Mata mineira e 183 assentamentos existentes, em Minas Gerais, no ano de 2003. Dos municípios, 12 foram identificados com maiores potencialidades para receber o projeto e a seleção pautou-se nos seguintes critérios: a existência, a organização e o dinamismo do Conselho Municipal de Desenvolvimento Rural Sustentável; disponibilidade de área adequada para a construção do viveiro e da unidade de processamento; facilidade para o escoamento da produção; motivação e envolvimento dos atores políticos; a experiência com a fruticultura e a produção orgânica; dotação de água e energia elétrica, e condiçõos das estradas.

Com relação aos assentamentos, devido ao seu número, outros critérios tiveram que ser acrescentados, como distribuição no Estado, mediadores, ano da criação e número de famílias. A opção foi pela Região Noroeste do Estado, pois possuía 56\% dos assentamentos, que estavam concentrados em 13 municípios. 
Para a seleção do assentamento, mais alguns critérios foram adicionados: interesse e motivação dos trabalhadores e lideranças; história de luta e organização; a organização da Associação dos Assentados e a sua dinâmica e atuação; a experiência em fruticultura e a produção orgânica; a facilidade para escoamento da produção; a infra-estrutura disponível; disponibilidade da área de uso coletivo; dotação de água e energia elétrica; e condições de conservação das estradas. ${ }^{13}$

Do conjunto de municípios e assentamentos visitados, o município de Guidoval, na Zona da Mata mineira, e o PA Nova Lagoa Rica, em Paracatu, foram selecionados. Em Guidoval, o projeto começou com 43 produtores familiares e no assentamento com 86. Em ambas as localidades o sistema de conversão orgânico foi introduzido, tendo-se, atualmente, em Guidoval, 32 produtores certificados e 22 em conversão. No assentamento, os produtores rurais ainda estão no processo de conversão, podendo obter a certificação no final de 2005.

$\mathrm{Na}$ fase inicial da pesquisa, foram identificados os principais atores institucionais, internos e externos ao projeto. ${ }^{14}$ Com isso, foi possível consolidar contatos, explicitar objetivos e obter o envolvimento das instituições, transformando a proposta de intervenção em um empreendimento coletivo.

Para a implementação das ações nas duas localidades, equipes interdisciplinares foram formadas e visitas mensais foram programadas. A ordem de ocorrência das visitas foi definida em função das normas de certificação. Primeiro, enfatizando a propriedade e o seu entorno, depois o entorno da área a ser escolhida na propriedade, passando, ao mesmo tempo, pela família e a residência do proprietário para, finalmente, chegar à escolha do local a ser cultivado, a identificação das frutas a serem cultivadas e a delimitação da área para a construção da infra-estrutura para a produção orgânica. Reuniōes, cursos e discussões em grupos foram as estratégias empregadas em todas as visitas, visando a capacitação para o empreendimento da fruticultura orgânica. Em função da necessidade de

\footnotetext{
${ }^{13}$ Evidentemente, os critérios que direcionaram para a escolha da melhor situação a ser trabalhada decorreram das condições em que o projeto foi desenvolvido, com restrições orçamentárias e de tempo. Qualquer outro assentamento poderia ser escolhido, mas as condições que refletem o assentamento irão requerer a extensão do arranjo organizacional e a ampliação do tempo de intervenção técnica-científica. Por exemplo, se uma associação não está organizada, isto implica necessidade de intervenção com essa finalidade.

14 Deve-se acrescentar que, simultaneamente, a divulgação do projeto ocorreu por meio de palestras em algumas instituições, tais como Sebrae/Belo Horizonte, FINEP/Rio de Janeiro, Fundação Banco do Brasil/Paracatu e INCRA/Belo Horizonte.
} 
envolvimento maior com os participantes do projeto, duas alterações ocorreram: as visitas ao município de Guidoval passaram a ser semanais e dois técnicos foram instalados no município de Paracatu.

Todas as visitas eram programadas e organizadas pela Associação dos Assentados e pela Comissão Municipal de Desenvolvimento Rural Sustentável. Conforme a identificação das distorções na implementação das açôes, a Coordenação do projeto na UFV era comunicada. As soluções ocorriam por meio de contatos telefônicos e e-mails, ou por deslocamentos, tanto dos representantes à Viçosa, quanto da Coordenação às áreas do projeto.

Apesar disso, os entraves ao andamento do projeto esteve restrito ao envolvimento das instituições locais. Ao trabalhar com a Associação dos Assentados e com a Comissão Municipal de Desenvolvimento Rural Sustentável, o projeto foi envolvido pela política local, em áreas consideradas das mais complexas de Minas Gerais. Como o projeto previa a contrapartida municipal, isto não ocorreu, no início, com a Prefeitura de Paracatu e foi muito lenta com a de Guidoval, o que atrasou o andamento do projeto. Além disso, as disputas políticas entre as facções locais atingiram a execução do projeto, chegando ao boicote, à destruição das atividades que já tinham sido implementadas e à inércia proposital.

Viagens e reuniōes foram realizadas, tanto à Viçosa quanto às áreas do projeto, para solucionar os conflitos, o que evidenciou a importância da monitoria nessa iniciativa de inovação organizacional e tecnológica. Concluise que ela não deve se restringir às ações implementadas, mas, sobretudo, deve redirecionar iniciativas locais que não diferenciam entre conflitos que levam à emancipação social e aqueles que intensificam a exclusão social.

\section{Resultados alcançados}

O resultado tangível alcançado foi a produção de 210 toneladas de polpa de manga ubá orgânica com exportação concretizada para a Holanda. Em termos de produtor rural, a caixa de manga, produzida convencionalmente, era comercializada a $\mathrm{R} \$ 4,20$, passando a $\mathrm{R} \$ 6,00$, sob a produção orgânica. Para alcançar esse resultado, outros foram obtidos, como o treinamento de professores, de estudantes, de técnicos e de profissionais, como auditores para a 
certificação. Essa capacitação permitiu a atuação desses profissionais no treinamento dos produtores rurais, ${ }^{15}$ na elaboração do cadastro das propriedades, no geo-referenciamento das áreas e das árvores produtivas, o que permite o rastreamento do produto e a abertura de novos mercados de trabalho para esses profissionais, pois alguns deles foram contratados por empresas que atuam no mercado de orgânicos.

A instalação da infra-estrutura de produção de mudas e de processamentos de produtos nas duas localidades se constituiu na referência para a capacitação e legitimidade do projeto. $\mathrm{O}$ viveiro protegido, o viveiro pleno sol, o campo de sementes e de matrizes, a casa de nebulização, o laboratório de preparo de caldas e biofertilizantes e a unidade industrial permitiram a consolidação da proposta de que os produtores poderiam ser inseridos em um novo nicho de mercado como produtores de mudas orgânicas, frutos orgânicos e os seus derivados, como polpa, doces, geléias, passas e compotas. Em reunião realizada em Paracatu, com a participação do representante da Cáritas Diocesano, houve a identificação da possibilidade de utilizar a infra-estrutura introduzida por esta Instituição no assentamento para a produção de açúcar mascavo orgânico, a partir do cultivo da cana-de-açúcar orgânica.

Além disso, pelos contatos com o representante da Fundação Banco do Brasil, em Paracatu, houve, também, a elaboração de projetos de treinamento para estender o projeto para três outros assentamentos no município. Essa tendência também se verificou em Guidoval, pois o projeto envolveu 65 produtores rurais dos municípios de Rodeios, Pedra do Anta, Canaã, Urucânia e Piranga, todos na Zona da Mata. As áreas dessas propriedades estão em pousio* para a certificação orgânica. ${ }^{16}$ Isto evidencia a potencialidade do projeto ser disseminado, o qual deverá ser mais ampliado pelo projeto elaborado pela UFV-Orgânica para a Prefeitura de Guidoval. Nesta proposta, encaminhada à área de fruticultura do Ministério do Desenvolvimento Agrário, o objetivo é expandir a produção na região de Guidoval, com um aporte de recursos na ordem de um milhão de reais, parte dos quais já foi liberado para o município.

\footnotetext{
${ }^{15}$ Essas ações permitiram a elaboração de apostilas sobre a produção orgânica e manuais de processamento de abacaxi, de manga, de acerola, de goiaba, de caju e de maracujá.

* Estágio de passagem necessário à produção orgânica (N. E.)

${ }^{16}$ Com essa extensão do projeto, há a expectativa de que o volume de exportação passe a ser de 500 a 700 toneladas de polpa orgânica, além da de abacaxi e maracujá, provenientes do assentamento.
} 
A restrição que a inovação organizacional e tecnológica apresenta é a disponibilidade das instituições se estruturarem para atuarem dentro dos princípios previamente estabelecidos. Essa é a restrição maior para a disseminação do modelo, e não o produto ou a área a ser trabalhada. Essa predisposição, apesar da disponibilidade e envolvimento dos professores envolvidos com o objeto, não foi encontrada dentro da universidade. $\mathrm{Na}$ condução das pesquisas, em geral, a universidade possui o corpo técnico, conselhos, secretarias de parcerias institucionais e a fundação gestora dos recursos, mas não possui uma estrutura de estudos interdisciplinares, associando pesquisa e intervenção social, apesar de existirem diversos núcleos. Essa iniciativa é de professores que, em virtudes dos editais dos projetos, se agregam voluntariamente e é essa disponibilidade que permite a consolidação do atual grupo de pesquisa. ${ }^{17}$

Visando essa consolidação, principalmente pelas experiências negativas de projetos anteriores que acabam quando se encerra o convênio, foi criada a UFVOrgânica, ${ }^{18}$ uma organização que está dando continuidade ao projeto, interagindo com as instituiçôes anteriormente citadas e com outras que permitem a obtenção da sustentabilidade do projeto. Nesse sentido, a Empresa Goody Alimentos S/A-Sucos, localizada em Ubá, MG, se constituiu na referência de mercado para os produtores rurais envolvidos com o projeto. Eles visitaram a empresa, técnicos foram contratados por ela, havendo, atualmente, a consolidação de mecanismos que permitem a continuidade do projeto, após a conclusão do convênio com a FINEP.

Deve-se acrescentar que esta nova composição organizacional também foi proposta para os assentados. Para tanto, foram realizadas reuniōes com o Prefeito de Paracatu, com o Secretário da Agricultura, com os presidentes das diferentes Associações dos Assentados e com o representante do sindicato local de trabalhadores. Além de enviar os técnicos para o assentamento, a Empresa mostrou-se interessada, em função da participação de mais assentamentos no

\footnotetext{
17 De um grupo de 70 professores envolvidos na elaboração de planos de recursos hídricos, em 1996, vários subgrupos continuaram, agregando novas especialidades, especialmente em função dos novos conteúdos dos editais de pesquisa. Para ilustrar, tem-se os subgrupos de licenciamento ambiental, de gestão de recursos hídricos, de desenvolvimento local integrado e o da fruticultura orgânica.

18 Atualmente, a UFV-Orgânica está localizada em uma das casas cedidas pela Universidade, contando com a participação de três professores, três técnicos, sendo um com graduação, um com mestrado e um com doutorado, e 25 estagiários bolsistas. Os técnicos e os estagiários bolsistas são remunerados pela Empresa Goody Alimentos S/A. A função da UFV-Orgânica é capacitar novos produtores e continuar com as orientações técnicas e de auditoria para a manutenção da certificação.
} 
projeto, em construir uma unidade de processamento no município. Ressaltase que, em ambas as experiências, houve a necessidade de envolvimento da Prefeitura, que, juntamente com a Associação dos Assentados e com a Comissão Municipal de Desenvolvimento Rural, vinculados à UFV-Orgânica, permite que o projeto adquira a sua sustentabilidade.

\section{Conclusão}

O modelo de inovação organizacional e tecnológica acrescenta um outro enfoque para tratar de inovação, de tecnologia e a própria noção de organização. O seu significado se restringe ao envolvimento das instituiçôes em um processo de intervenção, direcionado à inclusão de segmentos sociais em novos nichos de mercado. Trabalhando com assentados e produtores familiares, instituições de pesquisa e de financiamento, Associação de Assentados, Comissão de Desenvolvimento Rural Sustentável e a organização certificadora, atores coletivos foram identificados, interações foram estabelecidas e conflitos superados, o que permitiu a inserção dos produtores familiares na produção da manga orgânica e a da empresa processadora na produção da polpa orgânica.

Não ocorreu a geração de nenhuma tecnologia inovadora, no seu sentido restrito. Pelo contrário, o inventário evidenciou as disponibilidades existentes, tornando necessária a implementação das ações entre as instituições para introduzir aquelas tecnologias no sistema produtivo orgânico. Essa ação realça o papel da monitoria e da avaliação no processo de pesquisa e de intervenção social sob dois aspectos: na superação de conflitos, corrigindo o curso das trajetórias, e na obtenção da sustentabilidade do projeto, após a sua conclusão com a instituição financiadora.

Organizacionalmente, identificou-se que as instituições locais, além de serem representações políticas e de serem o agente de reivindicações, podem adquirir novas funções, como a explicitada no artigo. Entretanto, essa assimilação é lenta e conflituosa, evidenciando a complexidade em apreender o desenvolvimento pela dimensão de sua organização institucional para a inclusão social. Como evidenciado, essa perspectiva é complementar às alternativas teóricas existentes. Elas não se substituem, mas atuam sobre atores econômicos distintos, uns com mais potencial de inserção econômica do que outros. A questão 
principal, como ilustrado, é sobre os que estão excluídos. Com isso, podese inferir que a complexidade do Sistema Nacional de Inovação não se constata apenas pelos seus componentes e suas relações, mas que ele deve contemplar conteúdos de subsistemas de inovação, onde o de inovação organizacional e tecnológica é um deles.

Tomando a universidade como referência de competências, as alternativas às pesquisas podem ocorrer quando a instituição financiadora, como a FINEP, elabora editais inovadores. É outra inferência associada ao conteúdo do edital e não, necessariamente, ao volume do seu recurso. Com a constatação da relevância dos subsistemas de inovação, centros de ensino e pesquisa agropecuários podem se constituir em atores institucionais na integração dos segmentos sociais ao desenvolvimento. Entretanto, novos direcionamentos devem ser estabelecidos. Não é questão de estrutura, mas de enfoque e de orientação da pesquisa tecnológica, que apenas oferta tecnologia, para a pesquisa-intervenção social, associando tecnologias e conhecimento científico a projetos de integração social.

\section{Bibliografia}

Albuquerque, E. M., Apresentação. Revista Brasileira de Inovação, v.3, n.1, p.913, 2004.

Berlan, J.-P.; Lewonti, R. C.; "The Political Economy of Hybrid Corn”, in Montly Review: 35-47, jul./ago., 1986.

Busch, L.; Lacy, W. B., Science, Agriculture, and the Politics of Research, Boulder: Westview Press, 1983.

Buttel, F. H.; Kenney, M.; Kloppenburg Jr., J., "From Green Revolution to Biorevolution: some observations on the changing technological bases of economics transformation in the Third World", in Economic Development and Cultural Change 34(1): 31-54, 1985. 
Castells, M., A Sociedade em Rede. A Era da Informação: economia, sociedade e cultura, São Paulo: Paz e Terra, v.1, 2000.

Callon, M., "As Reestruturações Industriais em torno dos Programas de Pesquisa e Desenvolvimento", in Witkowski, N. (org.), Ciência e Tecnologia Hoje, São Paulo: Editora Ensaio, 1995.

Embrapa. O Enfoque de Pesquisa e Desenvolvimento (P\&D) e sua implementação na Embrapa. Departamento de Pesquisa e Desenvolvimento, Brasília: Embrapa, DPD, 1993.

Foster, J. B., Marx's Ecology. Materialism and Nature, Nova York: Monthly Review Press, 2000.

Freeman, C., The "National System of Innovation in Historical Perspective", in Revista Brasileira de Inovação, v.3, n.1, p.15-34, 2004.

Goldstein, D. J., Biotecnología, universidad y politica, México: Siglo Veintiuno Editores, 1989.

"Third World Biotechnology. Latin American Development, and the Foreign Debt Problem”, in Peritore, N. P.; Galve-Peritore, A. K. (orgs.), Biotechnology in Latin América. Politics, Impacts, and Risks, Delaware: SR Books, 1995.

Howard, P., "A Pesquisa e o Desenvolvimento no Processo de Desenvolvimento Industrial”, in Kim, L.; Nelson, R.,N. (orgs.), Tecnologia, Aprendizado e Inovação. As experiências das economias de industrialização recente. Campinas: Editora da UNICAMP, 2005.

Kim, L.; Nelson, R. (orgs.) Tecnologia, Aprendizado e Inovação. As experiências das economias de industrialização recente, Campinas: Editora da UNICAMP, 2005.

Luckács, G., História e Consciência de Classe, Rio de Janeiro: Elfos E., 1989.

Mark, D., "As Políticas para Ciência, Tecnologia e Inovação nas Economias Asiáticas de Industrialização Recente", in Kim, L.; Nelson, R. (orgs.), Tecnologia, Aprendizado e Inovação. As experiências das economias de industrialização recente, Campinas: Editora da UNICAMP, 2005.

Mowery, D. C..; Rosenberg, N., Trajetórias da Inovação. Mudança Tecnológica nos Estados Unidos da América no Século XX, Campinas: Editora da UNICAMP, 2005. 
Muniz, J. N., "O Conhecimento Científico como Falsa Consciência Necessária", in Cadernos de Ciência \& Tecnologia, v.12, n.1/3, p.29-38. 1995.

; Ribeiro, C.A.A. S., "Interdisciplinaridade: a metodologia integrada na elaboração de planos diretores de recursos hídricos”, in da Silva, D. D.; Pruski, F. F. (orgs.), Gestão de Recursos Hidricos. Aspectos legais, econômicos, administrativos e sociais. Brasília: Secretaria de Recursos Hídricos/MMA, 2000.

Paez, M. L., "Modelo de Análise e Gestão de Sistemas de Inovação do Agronegócio: novos horizontes ou caos?", in Cadernos de Ciência \& Tecnologia, v.18, n.2, p.37-68, 2001.

Rogers, E., Diffusion of Innovations, Nova York: The Free Press, 2003.

Rosenberg, N., "Inside the Black Box: Tecnology and Economics", Nova York, Cambridge: University Press, 1984.

, "Science and Economic Development", in Nova Economia, v.6, n.2., p.9-22, 1996.

Sohn-Rethel, "A. Science as Alienated Consciousness", in Radical Science Journal, v.2, n.3, p.65-101, 1983.

Vailati, J.; Cortés, D.M. M.; Pirani, P. S. H., "Princípios e Procedimentos de Certificação de Produtos Orgânicos", in Stringheta, P. C.; Muniz, J. N. (orgs.), Alimentos Orgânicos. Produção, Tecnologia e Certificação, Viçosa: Editora UFV/ FINEP, 2003. 